University of Rhode Island

DigitalCommons@URI

Past Departments Faculty Publications (CELS) College of the Environment and Life Sciences

2008

\title{
Severity of alcohol withdrawal symptoms depends on developmental stage of Long-Evans rats
}

\author{
Chun-Shiang Chung \\ University of Rhode Island \\ Jian Wang \\ University of Rhode Island \\ Monh Wehman \\ Dennis E. Rhoads \\ University of Rhode Island
}

Follow this and additional works at: https://digitalcommons.uri.edu/cels_past_depts_facpubs

This is a pre-publication author manuscript of the final, published article.

Creative Commons License

(c) (i) $\Theta$

This work is licensed under a Creative Commons Attribution-Noncommercial-No Derivative Works 4.0 License.

\section{Citation/Publisher Attribution}

Chung, C.-S., Wang, J., Wehman, M., \& Rhoads, D. E. (2008). Severity of alcohol withdrawal symptoms depends on developmental stage of Long-Evans rats. Pharmacology Biochemistry and Behavior, 89(2), 137-144. doi: 10.1016/j.pbb.2007.12.002

Available at: https://doi.org/10.1016/j.pbb.2007.12.002

This Article is brought to you for free and open access by the College of the Environment and Life Sciences at DigitalCommons@URI. It has been accepted for inclusion in Past Departments Faculty Publications (CELS) by an authorized administrator of DigitalCommons@URI. For more information, please contact digitalcommonsgroup@uri.edu. 


\title{
Severity of Alcohol Withdrawal Symptoms Depends on Developmental Stage of Long-Evans Rats
}

\author{
Chun-Shiang Chung ${ }^{\mathrm{a}}$, Jian Wang ${ }^{\mathrm{a}}$, Monh Wehman ${ }^{\mathrm{b}}$, and Dennis E. Rhoads ${ }^{\mathrm{a}, \mathrm{b}}$ \\ aDepartment of Biochemistry, Microbiology and Molecular Genetics, University of Rhode Island, \\ Kingston RI 02881 USA \\ bepartment of Biology, Monmouth University, W. Long Branch, NJ 07764 USA
}

\begin{abstract}
To investigate alcohol dependency and the potential role of age of initial alcohol consumption, Long-Evans (LE) rats were fed an ethanol-containing liquid diet starting at postnatal (P) ages (days): P23-27 (juvenile), P35-45 (adolescent) or P65-97 (young adult). Severity of subsequent withdrawal symptoms was dependent on age when consumption began and on duration of alcohol consumption. Frequency of withdrawal seizures was highest for rats starting consumption as juveniles, intermediate for adolescents and lowest for adults. Normalized to body weight, alcohol consumption was significantly higher for adolescent and juvenile rats than for adults. SpragueDawley rats that began alcohol consumption as adolescents (P35) had a level of alcohol consumption identical to that of the adolescent LE rats but showed much lower frequency of withdrawal seizures when tested after 2, 3 and 5 weeks of alcohol consumption. Based on several indicators, the capacity of the juveniles to metabolize ethanol is equal to or exceeds that of adults. Recoveries from a single dose of ethanol ( $2.5 \mathrm{~g}$ ethanol $/ \mathrm{kg}$ body weight) were faster for juvenile $\mathrm{LE}$ rats than adults. The rate of decline in blood ethanol concentration was identical for juvenile and adult rats while the corrected ethanol elimination rate was higher for juveniles. The primary isozyme of alcohol dehydrogenase (ADH) in rat liver, $\mathrm{ADH}-3$, had a similar $\mathrm{Km}$ and higher activity in liver preparations from juveniles. In conclusion, LE rats beginning alcohol consumption as juveniles or adolescents develop a severe alcohol withdrawal syndrome that may not be attributed entirely to higher levels of consumption and was not explained by any obvious deficiencies in metabolism.
\end{abstract}

\section{Keywords}

adolescence; alcohol consumption alcohol dependency; alcohol metabolism; alcohol withdrawal; intoxication; Long-Evans rats

(C) 2007 Elsevier Inc. All rights reserved.

Address correspondance to: Dr. Dennis E. Rhoads, Department of Biology, Monmouth University, W.Long Branch NJ 07764 Phone: 732-571-3429; Fax: 732-263-5243; drhoads@monmouth.edu.

Publisher's Disclaimer: This is a PDF file of an unedited manuscript that has been accepted for publication. As a service to our customers we are providing this early version of the manuscript. The manuscript will undergo copyediting, typesetting, and review of the resulting proof before it is published in its final citable form. Please note that during the production process errors may be discovered which could affect the content, and all legal disclaimers that apply to the journal pertain. 


\section{Introduction}

Specific components of human alcohol abuse can be demonstrated in animals (reviewed in Crabbe et al., 1994; Becker, 2000). As a gauge of alcohol dependency in animal models, the severity of alcohol withdrawal symptoms can be assessed when alcohol exposure is abruptly terminated (e.g., Goldstein, 1972; Majchrowicz, 1975; 1981; Crabbe et al., 1991; Metten and Crabbe, 1996; Becker et al., 1997; Finn and Crabbe, 1997; Becker, 2000). Among severe withdrawal symptoms in humans, convulsive seizures are potentially lethal and occur in up to $15 \%$ of chronic alcoholics (Booth and Blow, 1993).

The frequency with which human alcohol consumption begins during and before adolescence has led to increased interest in studying the effects of alcohol on juvenile animals (reviewed by Witt, 1994; Spear, 2000; Hiller-Sturmhöfel and Swartzwelder, 2004; Spear and Varlinskaya, 2005; White and Swartzwelder, 2005). With a number of interesting parallels to adolescent humans, adolescent rats can serve as a model for studying effects of alcohol on the immature brain (reviewed by Spear, 2000). Important differences have emerged in comparing the acute effects of alcohol in adolescent and adult rats. Adolescent rats were more sensitive than adults to the effects of ethanol on memory processes and associated hippocampal function (Swartzwelder et al., 1995; Markwiese et al., 1998; White and Swartzwelder, 2005). In contrast, adolescent rats are less sensitive than adults to a number of effects of ethanol that are seen as potential cues to moderate alcohol consumption (reviewed in Spear and Varlinskaya, 2005). These include lessor sensitivities of adolescents to the sedative effects of ethanol and to ethanol-induced motor impairment. In part, this relative insensitivity has been associated with rapid development of acute tolerance during a single ethanol challenge. Tendencies toward increased alcohol consumption and rapid adaptation to the presence of ethanol could translate into a greater susceptibility to alcohol dependency. It is of interest then that adolescent Sprague-Dawley (SD) rats showed less signs of acute withdrawal following single sessions of alcohol exposure (Doremus et al., 2003; Varlinskaya and Spear, 2004) and appeared to be less susceptible than adults to induction of seizures during withdrawal from chronic alcohol (Acheson et al., 1999).

Comparisons among rodent strains and more direct selective breeding of new lines have been useful approaches in moving towards understanding the genetics of alcohol abuse (e.g., Kosobud and Crabbe, 1986; Crabbe et al., 1985; 1991; 1994). During preliminary screening of alcohol withdrawal symptoms, Long-Evans (LE) rats that began chronic alcohol consumption at an early age (25-35 days old) showed more severe withdrawal symptoms than either the more commonly used SD strain or LE rats that began alcohol consumption as adults. The present study characterized the susceptibility of juvenile and adolescent LE rats to the effects of chronic alcohol consumption and tested whether the difference in withdrawal severity resulted from differences in ethanol consumption or deficiences in ethanol metabolism. 


\section{Materials and Methods}

\section{Animals}

Male Long-Evans (LE) and Sprague-Dawley (SD) rats were obtained from Charles River Laboratories (Wilmington MA; Raleigh NC) and used after 3-14 days of acclimation to our animal facility. In addition, breeding pairs of LE rats (also obtained initially from Charles River Laboratories) were maintained as an additional source of animals already acclimated to our facility. Rats were maintained in a controlled temperature and humidity environment with a light cycle from 0700 to 1900 . In studies of chronic ethanol treatment, rats were housed individually and fed for up to five weeks with a preformulated liquid diet (Lieber and DeCarli, 1982; LD'82 Liquidiets, Bioserv Inc., Frenchtown NJ) that was presented in feeding tubes (Bioserv Inc.). The diet was prepared and administered according to the manufacturers specifications with a final ethanol concentration of $6.7 \%(\mathrm{v} / \mathrm{v})$ achieved by the end of the first week. Rats had unlimited access to the ethanol-containing diet and the amount of diet consumed was recorded daily for each rat. Based on consumption of ethanol diet the previous day, control rats were pair-fed an isocaloric ethanol-free formula (Bioserv Inc.). Based on results of initial trials and the generally accepted developmental progression for rats (Spear, 2000), rats were started on the liquid diets at one of three postnatal (P) ages (days): P23 to 27 (juvenile), P35 to 45 (adolescent) and P65-97 (young adult). Although a range of starting ages was used for each group, the administration period was as indicated. So for three weeks of diet administration, a P25 rat was tested at P46 whereas a P35 rat was tested at P56. Weights and average alcohol consumption were determined weekly. For alcohol dehydrogenase studies, ethanol-naïve animals were sacrificed by decapitation, livers and brains were removed by dissection and fractionated immediately or stored at $-70^{\circ} \mathrm{C}$ prior to use. All protocols involving rats were reviewed and approved by the Institutional Animal Care and Use Committees of University of Rhode Island and/or Monmouth University as prescribed in the Public Health Service Guide for Care and Use of Laboratory Animals.

\section{Alcohol withdrawal symptoms}

Rats consumed the ethanol-containing diet for a period of 2, 3 or five weeks. Rats were monitored for the appearance of specific ethanol withdrawal symptoms after being switched from the ethanol-containing diet to the control formula (thereby affecting ethanol withdrawal). Initial trials led to testing a single measure of withdrawal severity: frequency of a stereotypic escalating response resulting from relatively mild handling and consisting of hyperreflexia (frequently including vocalizations), induced running episodes and convulsive seizures. These symptoms of alcohol withdrawal are well established for rats through the work of Majchrowicz $(1975 ; 1981)$. Testing began with routine sensory stimuli associated with removing the cage from the rack and mild handling (rats were picked up by the tail and returned to the cage). The frequency with which seizures resulted from handling in this matter was calculated for each age group. A rat was scored as showing this withdrawal symptom only if it went through the full escalating response ending in a seizure and, thus, it is frequency of withdrawal seizures that is reported (see Figure 1). It should be emphasized that this study is focused on a single measure of alcohol withdrawal. A minimum of 4 hours of alcohol withdrawal occurred before testing began and handling occurred each hour 
thereafter until withdrawal symptoms were observed. For juvenile and adolescent rats, this was between 4 and 6 hours. This withdrawal symptom was not observed in adults with testing extended to 24 hours after withdrawal. The time when withdrawal symptoms might occur depends more on when the individual rat had its last 'drink' than when the alcoholcontaining diet was removed. The latter represents the limit of minimum withdrawal time but a given rat may not have consumed any of the diet for some period of time prior to actual withdrawal. In addition, pair-fed control rats were handled and tested for each age group to guard against the presence of any unusual seizure susceptibility that is independent of alcohol consumption and withdrawal.

\section{Injection of ethanol}

Ethanol was administered as described by Lumeng et al. (1979) with minor modifications. Juvenile (P23) and adult (P90) rats were given an intraperitoneal (i.p.) injection with a $20 \%$ $(\mathrm{v} / \mathrm{v})$ solution of ethanol ( $2.5 \mathrm{~g}$ ethanol $/ \mathrm{kg}$ of body weight) in sterile saline. Tail blood samples were collected in heparinized capillary tubes at $30 \mathrm{~min}$ and again at additional 45 minute intervals following injection. A $20 \mu \mathrm{l}$ sample of blood was drawn for each time point after injection of ethanol.

\section{Determination of blood ethanol concentration (BEC)}

To analyze BEC, the micromethod of Roach and Creaven (1968) was used without significant modification. Samples were analyzed for ethanol by gas chromatography (model 700 Capco Anaerobic Identification system, Sunnyvale, CA). The system included a thermal conductivity-95 mA current detector and helium as the carrier gas (flow rate of $120 \mathrm{ml} / \mathrm{min}$ ). The temperature of the column and detector was $110^{\circ} \mathrm{C}$ while the injection port temperature was $150^{\circ} \mathrm{C}$. The glass capillary column was $6 \mathrm{ft} \times 1 / 4$ inch (i.d.) and packed with $10 \% \mathrm{SP}$ 1000 and 100/120 chromosorb W AW. Retention time for ethanol was 2 min under the above conditions. The concentration of ethanol in the blood samples was calculated by comparing the peak height with that of an ethanol standard. Additional determinations of BEC were made using an enzymatic assay (NAD-ADH Assay Kit, Sigma Diagnostics, St. Louis MO).

\section{Intoxication scoring}

Following injection with ethanol (see above), behavioral analysis was used to rate each rat for signs of alcohol intoxication. At each time point before the tail blood sample was drawn, each rat was scored for intoxication (Majchrowicz, 1975). According to Majchrowicz's classifications, ethanol intoxication and the steps toward recovery following intoxication can be categorized by degrees of severity from neutrality through sedation, ataxia 1, ataxia 2 , ataxia 3, loss of righting reflex (LRR), coma and death. No symptom more severe than LRR was encountered with the dose used in this study. Therefore, the severity of ethanol intoxication was scored: 5 for LRR (unable to right itself within 3 seconds of being placed on its back), 4 for severe locomotor impairment (Majchrowicz's ataxia 3: broadly staggering gait if moves forward at all, no elevation of abdomen and pelvis, heavy general sedation and lethargy), 3 for intermediate locomotor impairment (Majchrowicz's ataxia 2: somewhat staggering gait, some elevation of abdomen and pelvis when moving forward), 2 for mild 
locomotor impairment (Majchrowicz's ataxia 1: heavier sedation, sluggish and uncoordinated but staggering gate not pronounced with sustained elevation of the abdomen and pelvis when moving forward), 1 for sedation without motor impairment, and 0 for neutrality (no sign of intoxication, normal body tone, startle reflex apparent). Five individual investigator scores were used to assess each rat's behavior at each time point and used to arrive at a composite intoxication score.

\section{Alcohol dehydrogenase (ADH)}

Alcohol dehydrogenase was enriched from liver and brain extracts using the method of Dalziel (1961) with some modification. Rat livers and brains (stored at $-70^{\circ} \mathrm{C}$ ) were thawed, cut into small pieces and homogenized in 10 volumes of $10 \mathrm{mM}$ Tris/ $\mathrm{HCl}(\mathrm{pH} 7.0)$ containing $0.5 \mathrm{mM}$ dithiothreitol. The homogenates were centrifuged at $4^{\circ} \mathrm{C}$ at $10,400 \mathrm{xg}$ for $1 \mathrm{hr}$ and the supernatant was centrifuged at 85,000 $\mathrm{xg}$ for another hr. The supernatants were collected for ammonium sulfate fractionation. Eighty percent of the enzyme is precipitated between 0.5 and 0.67 ammonium sulfate saturation (Dalziel, 1961). Ammonium sulfate $(300 \mathrm{~g} / \mathrm{l})$ was added to the supernatant with subsequent mixing at $4^{\circ} \mathrm{C}$ for $1 \mathrm{hr}$. After centrifugation (20,000 $\mathrm{xg}$ for $30 \mathrm{~min})$, ammonium sulfate (110g/liter) was added to the supernatant. This was stirred for $1 \mathrm{hr}$ and the suspension was centrifuged as before. The resulting pale-red precipitate containing the enzyme was then resuspended in $3 \mathrm{ml}$ of $10 \mathrm{mM}$ Tris buffer, pH 7.4, and desalted using a Bio Rad 10 DG desalting column. The enzyme solutions were stored at $-70^{\circ} \mathrm{C}$ and used for $\mathrm{ADH}$ activity and electrophoresis.

\section{Measurement of ADH activity}

The ADH activity was measured spectrophotometrically as described by Julia et al. (1987). The absorbance change at $340 \mathrm{~nm}$ for NADH production was measured at $30^{\circ} \mathrm{C}$ in a Gilford Response II spectrophotometer (Ciba Corning Diagnostics Corp., Oberlin, OH). The activities of $\mathrm{ADH}$ isozymes from rat tissues were determined in $0.1 \mathrm{M}$ glycine $/ \mathrm{NaOH}$ buffer (pH 10.0) with coenzyme and different substrates: $4 \mathrm{mM} \mathrm{NAD}^{+}$and $1 \mathrm{mM}$ octanol, respectively, for $\mathrm{ADH}-2$, or $2.4 \mathrm{mM} \mathrm{NAD}^{+}$and $33 \mathrm{mM}$ ethanol, respectively, for $\mathrm{ADH}-3$. Enzyme activity was expressed as Units of activity ( $\mu$ moles of NADH produced $/ \mathrm{min}$ ). Kinetic constants for ADH-3 were estimated from a Lineweaver-Burk plot of activity measured over a range of ethanol concentrations from 0.2 to $12.5 \mathrm{mM}$. Starch gel electrophoresis using 2-buten-1-ol as the substrate for ADH activity staining was carried out as described by Julia et al. (1987) but was used only to confirm the presence of ADH-2 and/or ADH-3 in the extracts.

\section{Data Analysis}

Comparisons among age groups and strains were evaluated by analysis of variance (ANOVA) with Bonferonni post tests or where appropriate by repeated-measures ANOVA. Significance was set at $p<0.05$. 


\section{Results}

\section{Severity of withdrawal syndrome}

Long-Evans rats showed marked differences in the frequency of severe ethanol withdrawal symptoms as a function of the age at which alcohol consumption began and duration of alcohol consumption (Figure 1). For rats that began consuming alcohol as juveniles (23-27 days old), 33\% progressed through an escalating pattern of hyperreflexia, running episodes and convulsive seizure during alcohol withdrawal after 2 weeks of alcohol consumption. This seizure-frequency increased with length of time consuming the alcohol diet, reaching nearly $100 \%$ after 5 weeks of alcohol consumption when consumption began as juveniles. In addition, withdrawal seizures tended to be more severe after 5 weeks of alcohol consumption with a mortality rate of $43 \%$ (13 out of 30 ) following prolonged convulsive episodes. Rats beginning alcohol consumption as adolescents (35-45 days old) showed a moderately high frequency of withdrawal seizures after 3 weeks and reached approximately $50 \%$ after consuming the ethanol diet for a total of 5 weeks. The severity of the convulsive episodes was less with mortality reduced to $17 \%$ (5 out of 30 ) after completing five weeks of the feeding paradigm. In sharp contrast to these results, LE rats beginning alcohol consumption as young adults (65-97 days old) showed essentially no signs of alcohol withdrawal following 5 weeks of alcohol consumption. Thus, there was an apparent correlation between ethanol withdrawal severity and age of initial alcohol consumption in these LE rats.

For comparison, age-matched pair-fed control rats were tested for all groups. The stereotypic pattern of hyperreflexia, running episodes and convulsive seizures was not seen in any pair-fed control rats at any age and thus was specific in this study to alcohol consumption and withdrawal. This rules out a general sensitivity of this strain to convulsions during handling or following administration of liquid diets. Also for comparison, one group of adolescent (P35) Sprague-Dawley rats was tested. Subsequent withdrawal symptoms were low with only 1 out of 12 rats showing the stereotypic alcohol withdrawal response after 5 weeks of ethanol consumption. Thus, the sensitivity of LE rats to developing a strong alcohol withdrawal syndrome when they begin alcohol consumption as adolescents is not a characteristic of all adolescent rats.

Average alcohol consumptions differed significantly $[\mathrm{F}(3,34)=23.41, \mathrm{p}<0.001]$ among groups with higher average alcohol consumption by younger rats when normalized to body weight (Figure 2). Alcohol consumption by juvenile rats (P23-27) was significantly higher than that of the P35-45 adolescent group $(\mathrm{p}<0.01)$ and than that of the P65-97 adult group $(\mathrm{p}<0.001)$. Alcohol consumption by the adolescent group was also significantly higher than that of the adults $(\mathrm{p}<0.01)$. In all three age groups, rats gained weight during the feeding schedule (Table1). However, analysis of final weights showed significant differences with ethanol-fed rats weighing up to $20 \%$ less than pair-fed controls (Table 1) at the end of the five week period. The weight difference was significant within each age group $(\mathrm{p}<0.01$ for P25 LE, p $<0.001$ for P35 LE and P90 LE). Comparison of alcohol consumption by rats starting alcohol consumption either as juveniles or as adults showed significant differences between age groups $[\mathrm{F}(9,61)=18.43, \mathrm{p}<0.001]$ (Figure 3 ). Those that began alcohol 
consumption as juveniles consumed more diet normalized to body weight each week of the 5 week period.

Comparison of adolescent LE and SD rats showed nearly identical levels of average alcohol consumption between the two strains (Figure 2). The SD strain showed weight gain comparable to what was seen with the LE rats and, like LE, ethanol-fed SD rats weighed significantly less $(\mathrm{p}<0.001)$ than the corresponding pair-fed controls (Table 1). Thus, in both average alcohol consumption and weight gain, there was no significant difference between the adolescents of the two strains. This is important because it contrasts sharply with the marked difference in frequency of alcohol withdrawal seizures between the two strains (Figure 1).

\section{Ethanol elimination rates and recovery from intoxication}

Following a single injection with ethanol, the blood ethanol concentration (BEC) of ethanolnaïve adult $\mathrm{LE}$ rats $(\mathrm{P} 90$, mean weight $=349 \mathrm{~g})$ was significantly higher than that of immature LE rats $(\mathrm{P} 23$, average weight $=50 \mathrm{~g})$ at all time points $(\mathrm{p}<0.01)$ (Figure 4$)$. Extrapolating to the $y$ intercept of the regression lines for the decrease in BEC with time, maximum BEC was significantly lower $(p<0.005)$ for juveniles $(285 \mathrm{mg} / \mathrm{dl})$ than for adults $(395 \mathrm{mg} / \mathrm{dl})$. The slopes of these regression lines were $67 \mathrm{mg} / \mathrm{dl} / \mathrm{hr}$ for juveniles and 66 $\mathrm{mg} / \mathrm{dl} / \mathrm{hr}$ for adults indicating there was no significant difference in the rate of decrease of BEC. However, accounting for the differences in mass and ethanol distribution (Widmark's formula; Kalant, 1971), the corrected ethanol elimination rates were significantly higher $(p<0.01)$ for juveniles $(587 \mathrm{mg} / \mathrm{kg} / \mathrm{hr})$ than adults $(416 \mathrm{mg} / \mathrm{kg} / \mathrm{hr})$.

The severity of ethanol intoxication was scored for each rat prior to drawing blood samples and averaged for each time point (Figure 5). Adult rats showed significantly more severe intoxication responses than immature rats at each of the time points ( $p<0.01$ for all time points). Adult rats required up to 255 minutes to recover to neutrality, compared to 165 minutes for juveniles. These results were consistent with the higher average BEC in adults (Figure 4) and the faster corrected ethanol elimination rates in juveniles.

\section{Comparison of ADH activity between juvenile and adult L/E rats}

Liver ADH-3 activity (Table 2) was significantly higher ( $<<0.001)$ in juvenile LE rats compared to their adult counterparts. Liver ADH-2 activity was also significantly higher $(\mathrm{P}<0.001)$ in juveniles (Table 2). As expected, the brain ADH-2 activities of immature and adult rats were very low (less than $10 \%$ of the liver activity) and there was no significant difference between the two age groups (Table 2). Starch gel electrophoresis with activity staining of ADH from brain and liver homogenates was used to verify the presence of isozymes of ADH which had been operationally defined using different substrate specificity. ADH from liver and brain of immature and adult rats had the same patterns in the starch gel electrophoresis (data not shown). As expected, ADH-2 was detected as an anodic isoenzyme in both brain and liver and ADH-3 was detected as a cathodic isoenzyme in liver but not brain tissue. The Michaelis constants (Km values) from Lineweaver-Burk plots for ADH-3 were not significantly different for ADH-3 from juveniles $(\mathrm{Km}=0.49 \mathrm{mM})$ and adults $(\mathrm{Km}$ 
$=0.51 \mathrm{mM})$. Thus, the difference in ADH-3 activities is most likely associated with the amount of enzyme present rather than the kinetic properties of the enzyme.

\section{Discussion}

Cessation or reduction of alcohol consumption after periods of prolonged alcohol intake results in an alcohol withdrawal syndrome in humans and other animals. Physical withdrawal symptoms represent a gauge of the severity of alcohol dependency. Alcohol withdrawal symptoms range from anxiety, mild tremors and hyperreflexia to severe convulsions and seizures (Victor and Brausch, 1967; Goldstein, 1972; Majchrowicz, 1975; 1981; Ballenger and Post, 1978; Crabbe et al., 1991; Babor et al., 1992; Booth and Blow, 1993; Metten and Crabbe, 1996; Becker et al., 1997; Finn and Crabbe, 1997; Metten et al., 1998; Becker, 2000). In general, the physical symptoms associated with alcohol withdrawal reflect hyperexcitation in the central nervous system following chronic consumption of alcohol. The physical symptoms associated with alcohol withdrawal are considered a potent force in promoting further alcohol consumption (Becker et al., 1997) and thus it is of interest to define any conditions or genetic factors associated with pronounced symptoms of alcohol withdrawal (Crabbe et al., 1991).

The present study showed for alcohol withdrawal seizures such factors include the developmental stage at which rats begin alcohol consumption. Given the relatively narrow window through which sexual maturation occurs in rats (Spear, 2000), it is clear for the LE strain that immature rats show a high frequency of alcohol withdrawal seizures that were not seen when the rats begin alcohol consumption following sexual maturation as young adults. There is a marked decrease in the severity of alcohol withdrawal symptoms that appears to be correlated in the LE rats with the progression from juvenile to adolescent to adult in terms of the age that alcohol consumption began. As a gauge of alcohol dependency, differences in the frequency of withdrawal seizures when LE rats began alcohol consumption as juveniles and adolescents were characterized by their overall severity (mortality reached $42 \%$ after prolonged convulsive episodes), the ease with which they could be triggered (mild handling), and the speed with which they developed. Withdrawal symptoms began developing within two weeks for LE rats beginning consumption as juveniles and within 3 weeks for those beginning consumption as adolescents. This was in sharp contrast to rats that began consumption as adults and showed essentially no withdrawal symptoms after five weeks of alcohol consumption. Although the adult LE rats were resistant to alcohol dependency by the standard applied in this study, other approaches have shown that a relatively severe alcohol withdrawal syndrome can be induced in adult LE rats using ethanol vapor inhalation (Ruwe et al., 1986) which yielded BEC up to $400 \mathrm{mg} / \mathrm{dl}$. Liquid diets generally result in BEC below 200mg/dl (Gonzales et al., 1987; Gonzales et al., 1991; Wang, Chung and Rhoads, unpublished results). Longer periods of ethanol administration have been used in studying chronic effects of ethanol on adult LE rats (Thinschmidt et al., 2003) and it appears that withdrawal symptoms can be elicited in adult LE rats with significantly longer periods of chronic alcohol consumption (Chung, Wang and Rhoads, unpublished) though these were much less severe than those reported here for LE rats beginning consumption as juveniles or adolescents or for those induced using ethanol vapor inhalation (Ruwe et al., 1986). Absence of seizures in any pair-fed control LE rats 
rules out any generalized seizure susceptibility independent of ethanol consumption and withdrawal.

The relationship between the severity of withdrawal symptoms and BEC is relevant to interpretation of the present results because immature rats consumed significantly more ethanol, normalized to body weight, than the adults. On the most basic level, differences in alcohol dependency at different ages could be explained by differences in alcohol consumption or by deficiencies in alcohol metabolism or clearance. Spear and coworkers have reported a tendency of immature rats to consume more liquids and food than their adult counterparts (see Doremus et al., 2005). This is supported by the current study with juveniles and adolescents consuming significantly more of the ethanol-containing diet and thus consuming more ethanol. Monitoring consumption of the control diet helped confirm that normalized to body weight more diet was being consumed by the immature animals, presumably a reflection of the high caloric demands of relatively rapid periods of growth. Followed over several weeks, the juvenile rats consistently consumed more diet and hence more alcohol than their adult counterparts (Figure 3). Given the overall tendency of immature rats to eat and drink more than their adult counterparts, the greater alcohol consumption here is probably a secondary consequence of this more general tendency. Nevertheless, this raises the question of whether the higher alcohol consumption may alone explain the greater alcohol withdrawal syndrome. In relating alcohol consumption to subsequent signs of dependency, the limited comparison between adolescent LE and SD rats is therefore crucial. Nearly identical levels of alcohol consumption (18 g ethanol $/ \mathrm{kg} /$ day) were observed with the two strains over the 5 week course of ethanol consumption with alcohol consumption beginning as adolescents. However, SD rats that began alcohol consumption as adolescents showed very low frequency of subsequent withdrawal seizures compared to the LE strain. Thus, elevated consumption, which was identical between the two strains, is not necessarily linked to withdrawal seizures when alcohol consumption begins in adolescence. This implies that elevated consumption may not fully account for the differences in withdrawal severity of LE rats when they begin consumption as juveniles or adolescents when compared to the relative resistance of those that began consumption as adults. That SD rats beginning alcohol consumption as adolescents did not show any hightened withdrawal response is consistent with studies wherein there was no report of unusual alcohol dependency using two-week-old SD rats (Sun et al., 1987). The extent of strain specificity for this developmental stage-specific alcohol dependency requires more study as does the underlying brain systems supporting this susceptibility.

If immature LE rats were deficient in some aspect of alcohol metabolism then actual ethanol exposure might be even higher than expected. This was not the case. Ethanol metabolism was assessed by both indirect and direct measures in a comparison of juvenile and adult rats. Following a single injection of ethanol $(2.5 \mathrm{~g} / \mathrm{kg})$, the corrected ethanol elimination rate of immature rats was significantly higher than adult rats. It should be noted that the slope of the line for the decrease in BEC with time was not different between the two age groups. Therefore, the difference in ethanol elimination rate could be due to a difference in tissue distribution of ethanol between the smaller immature and much larger adult rats. Nevertheless, there was a good temporal correlation between BEC decline and recovery from the intoxicating dose of ethanol with recovery faster in the immature rats than in their 
adult counterparts. Corrected elimination rates for LE rats are in reasonable agreement with values reported by others for adolescent LE (Webb et al., 2002) and adult Sprague-Dawley (Koivula \& Lindros, 1975) rats. Direct measures of ADH activities in liver (which contains $\mathrm{ADH}-2$ and ADH-3 isoenzymes) of immature rats were significantly higher than those of adult rats. Other studies have shown that ADH levels are fully developed by postnatal day 20-30 in other rat strains (Boleda et al., 1992; Horton \& Mills, 1979; Lad et al., 1984) rats. The ADH-2 isozyme cannot be saturated with short-chain alcohols (e.g., methanol, ethanol and butanol) even at fairly high concentrations (Julia et al., 1987). Thus, it is the ADH-3 isozyme that it considered more important in ethanol elimination and it is significant that ADH-3 activity was $44 \%$ higher in juvenile LE rat liver than in that of the adult liver. There was no difference between the two age groups of LE rats in the low levels of ADH activity detectable in brain (which contains only ADH-2). The Km values for liver ADH-3 showed no difference between the two age groups, and the $\mathrm{Km}$ values were within the normal range reported (0.10-1.96 mM) (Babor, 1992). The difference then in liver ADH enzyme activity under Vmax conditions is most likely the result of higher enzyme content per mg protein (Lad et al., 1984) in immature LE rats. Together, these results indicate there was no deficiency in alcohol metabolism, and, if anything, a greater capacity to clear alcohol in the juvenile LE rats. In general, studies of alcohol elimination and ADH activities in other strains have indicated that adolescent rats have the same or higher levels of ethanol metabolism compared to their adult counterparts (reviewed in Spear and Varlinskaya, 2005), a conclusion that is supported by this study with LE rats. In a comparison of intoxication (loss of righting reflex) and ethanol elimination rates between male and female P45 LE rats, Webb et al. (2002) showed that LRR was induced in adolescent LE rats at a slightly higher dose of ethanol $(3 \mathrm{~g} / \mathrm{kg})$. They also reported ethanol elimination rates that support the conclusion that there is no deficiency in ethanol metabolism in the less mature rats of this strain.

Rats in each of the age groups gained weight while consuming the ethanol diet however they weighed about $20 \%$ less on average than pair-fed controls. This was true for adults as well as immature rats and for adolescents of both the LE and SD strains. Thus, it would not appear to be a factor in the differences seen in appearance of alcohol withdrawal seizures. The reduced weight gain of the ethanol-fed rats compared to the control rats agreed with the findings of others (e.g., Gonzales et al., 1987; Gonzales et al., 1991). While the underlying cause of weight differences in otherwise pair-fed rats is not known, it was eliminated within two weeks of switching ethanol-fed rats to the control diet (Chung and Rhoads, unpublished results) and appears to be fully reversible at this stage.

In conclusion, the availability of LE rats and the speed and severity with which alcohol withdrawal symptoms appear in juvenile rats, make this an excellent model system both for better understanding genetic factors associated with alcohol dependency and for identifying the potentially unique risks associated with adolescent alcohol abuse.

\section{Acknowledgments}

The authors thank Ms. Monica Cassity (University of Rhode Island) for assistance with animal care and Sean Casavant, Philip Empey, Bruno Soffientino and Joe Susa (University of Rhode Island) and Sean Bhattacharya, Lisa Stickle, Reuven Feldman, Jennifer Huggan, Ashley Toth, and Joseph McLaughlin (Monmouth University) for their 
help in preparing and administering the liquid diet, monitoring alcohol withdrawal, collecting blood samples and/or enzyme analyses. We thank Dr. Jay Sperry (University of Rhode Island) for providing and assisting with the gas chromatography. Early portions of this work were supported by NIAAA grant AA07848.

\section{References}

Acheson SK, Richardson R, Swartzwelder HS. Developmental changes in seizure susceptibility during ethanol withdrawal. Alcohol. 1999; 18:23-6. [PubMed: 10386661]

Babor TF, Hofmann M, DelBoca FK, Hesselbrock V, Meyer RE, Dolinsky ZS, Rounsaville B. Types of alcoholics, I. Evidence for an empirically derived typology based on indicators of vulnerability and severity. Arch Gen Psychiatry. 1992; 49:599-608. [PubMed: 1637250]

Ballenger JC, Post RM. Kindling as a model for alcohol withdrawal syndromes. Br J Psychiatry. 1978; 133:1-14. [PubMed: 352467]

Becker HC. Animal models of alcohol withdrawal. Alcohol Res Health. 2000; 24:105-13. [PubMed: 11199277]

Becker HC, Diaz-Granados JL, Weathersby RT. Repeated ethanol withdrawal experience increases the severity and duration of subsequenct withdrawal seizures in mice. Alcohol. 1997; 14:319-26. [PubMed: 9209546]

Boleda MD, Farres J, Guerri C, Pares X. Alcohol dehydrogenase isoenzymes in rat development, effect of maternal ethanol consumption. Biochem Pharmacol. 1992; 43:1555-61. [PubMed: 1567477]

Booth BM, Blow FC. The kindling hypothesis: further evidence from a US national study of alcoholic men. Alcohol Alcohol. 1993; 28:593-8. [PubMed: 8274184]

Crabbe JC, Merrill C, Belknap JK. Acute dependence on depressant drugs is determined by common genes in mice. J Pharmacol Exp Ther. 1991; 257:663-7. [PubMed: 2033513]

Crabbe JC, Kosobud A, Young ER, Tam BR, McSwigan JD. Bidirectional selection for susceptibility to ethanol withdrawal seizures in Mus musculus. Behav Genet. 1985; 15:521-36. [PubMed: 4096679]

Crabbe JC, Belknap JK, Buck KJ. Genetic animal models of alcohol and drug abuse. Science. 1994; 264:1715-23. [PubMed: 8209252]

Dalziel K. The preparation and properties of crystalline alcohol dehydrogenase from liver. Biochem J. 1961; 80:440-5. [PubMed: 13719495]

Doremus TL, Brunell SC, Varlinskaya EI, Spear LP. Anxiogenic effects during withdrawal from acute ethanol in adolescent and adult rats. Pharmacol Biochem Behav. 2003; 75:411-8. [PubMed: 12873633]

Doremus TL, Brunell SC, Rajendran P, Spear LP. Factors influencing ethanol consumption in adolescent relative to adult rats. Alcohol Clin Exp Res. 2005; 29:1796-1808. [PubMed: 16269909]

Finn DA, Crabbe JC. Exploring alcohol withdrawal syndrome. Alcohol Health Res World. 1997; 21:149-156. [PubMed: 15704352]

Goldstein DB. Relationship of alcohol dose to intensity of withdrawal signs in mice. J Pharmacol Exp Ther. 1972; 180:203-15. [PubMed: 5062297]

Gonzales RA, Ganz N, Crews FT. Variations in membrane sensitivity of brain region synaptosomes to the effects of ethanol in vitro and chronic in vivo treatment. J Neurochem. 1987; 49:158-62. [PubMed: 3585327]

Gonzales RA, Crews FT. Chronic ethanol inhibits receptor-stimulated phosphoinositide hydrolysis in rat liver slices. Alcohol. 1991; 8:131-6. [PubMed: 1648364]

Hiller-Sturmhöfel S, Swartzwelder HS. Alcohol's effects on the adolescent brain. What can be learned from animal models. Alcohol Research Health. 2004/5; 28:213-21.

Horton AA, Mills DJ. Developmental patterns of alcohol dehydrogenase and aldehyde dehydrogenases in homogenates and subcellular fractions of rat liver. Mech Age Develop. 1979; 11:363-70.

Julia P, Farres J, Pares X. Characterization of three isoenzymes of rat alcohol dehydrogenase, tissue distribution and physical and enzymatic properties. Europ J Biochem. 1987; 162:179-89.

[PubMed: 3816781] 
Kalant, H. Absorption, diffusion, distribution and elimination of ethanol: effects on biological membranes. In: Kissin, B.; Begleiter, H., editors. The Biology of Alcoholism Vol.1: Biochemistry. Ridley's Book Bindery Inc; New York: 1971.

Koivula T, Lindros KD. Effects of long term ethanol treatment on aldehyde and alcohol dehydrogenase activities in rat liver. Biochem Pharmacol. 1975; 24:1937-42. [PubMed: 1212243]

Kosobud A, Crabbe JC. Ethanol withdrawal in mice bred to be genetically prone or resistant to ethanol withdrawal seizures. J Pharmacol Exp Ther. 1986; 238:170-7. [PubMed: 3723396]

Lad PJ, Shoemaker WJ, Leffert HL. Developmental changes in rat liver alcohol dehydrogenase. Develop Bio. 1984; 105:526-9. [PubMed: 6383901]

Lieber CS, DeCarli LM. The feeding of alcohol in liquid diets: two decades of applications and 1982 update. Alcoholism Clin Exp Res. 1982; 6:523-31.

Lumeng L, Bosron WF, Li TK. Quantitative correlation of ethanol elimination rates in vivo with liver alcohol dehydrogenase activities in fed, fasted and food-restricted rats. Biochem Pharmacol. 1979; 28:1547-51. [PubMed: 475866]

Majchrowicz E. Induction of physical dependence upon ethanol and the associated behavioral changes in rats. Psychopharmacologia. 1975; 43:245-54. [PubMed: 1237914]

Majchrowicz E. Reversal in central nervous system function during ethanol withdrawal in humans and experimental animals. Fed Proc. 1981; 40:2065-72. [PubMed: 7227562]

Markwiese BJ, Acheson SK, Levin ED, Wilson WA, Swartzwelder HS. Differential effects of ethanol on memory in adolescent and adult rats. Alcohol Clin Exp Res. 1998; 22:416-21. [PubMed: 9581648]

Metten, P.; Crabbe, JC. Dependence and withdrawal. In: Deitrich, RA.; Ervin, VG., editors. Pharmacological Effects of Ethanol on the Nervous System. CRC Press; Boca Raton, FL: 1996. p. 269-90.

Roach MK, Creaven PJ. A micro-method for the determination of acetaldehyde and ethanol in blood. Clin Chim Acta. 1968; 21:275-8. [PubMed: 5673995]

Ruwe WD, Bauce L, Flemons WW, Veale WL, Pittman QJ. Alcohol dependence and withdrawal in the rat. An effective means of induction and assessment. J Pharmacol Meth. 1986; 15:225-34.

Silveri MM, Spear LP. Decreased sensitivity to the hypnotic effects of ethanol early in ontogeny. Alcohol Clin Exp Res. 1998; 22:670-6. [PubMed: 9622449]

Spear LP. The adolescent brain and age-related behavioral manifestations. Neurosci Biobehav Rev. 2000; 24:417-63. [PubMed: 10817843]

Spear LP. Modeling adolescent development and alcohol use in animals. Alcohol Res Health. 2000; 24:115-23. [PubMed: 11199278]

Spear LP, Varlinskaya EI. Adolescence: alcohol sensitivity, tolerance and intake. Rec Develop Alcohol. 2005; 17:143-59.

Sun GY, Huang HM, Chandrasekhar R, Lee DZ, Sun AY. Effects of chronic ethanol administration on rat brain phospholipid metabolism. J Neurochem. 1987; 48:974-80. [PubMed: 3027265]

Swartzwelder HS, Wilson WA, Tayyeb MI. Differential sensitivity of NMDA receptor-mediated synaptic potentials to ethanol in immature verse mature hippocampus. Alcohol Clin Exp Res. 1995; 19:320-3. [PubMed: 7625564]

Thinschmidt JS, Walker DW, King MA. Chronic ethanol treatment reduces the magnitude of hippocampal LTD in the adult rat. Synapse. 2003; 48:189-97. [PubMed: 12687638]

Varlinskaya EI, Spear LP. Acute ethanol withdrawal (hangover) and social behavior in adolescent and adult male and female rats. Alcohol Clin Exp Res. 2004; 28:40-50. [PubMed: 14745301]

Victor M, Brausch C. The role of abstinence in the genesis of alcoholic epilepsy. Epilepsia. 1967; 8:120. [PubMed: 4961509]

Webb B, Burnett PW, Walker DW. Sex differences in ethanol-induced hypnosis and hypothermia in young Long-Evans rats. Alcohol Clin Exp Res. 2002; 26:695-704. [PubMed: 12045479]

White AM, Swartzwelder HS. Age-related effects of alcohol on memory and memory-related brain funcion in adolescents and adults. 2005; 17:161-76.

Witt ED. Mechanisms of alcohol abuse and alcoholism in adolescents: a case for developing animal models. Behav Neur Bio. 1994; 62:168-77. 


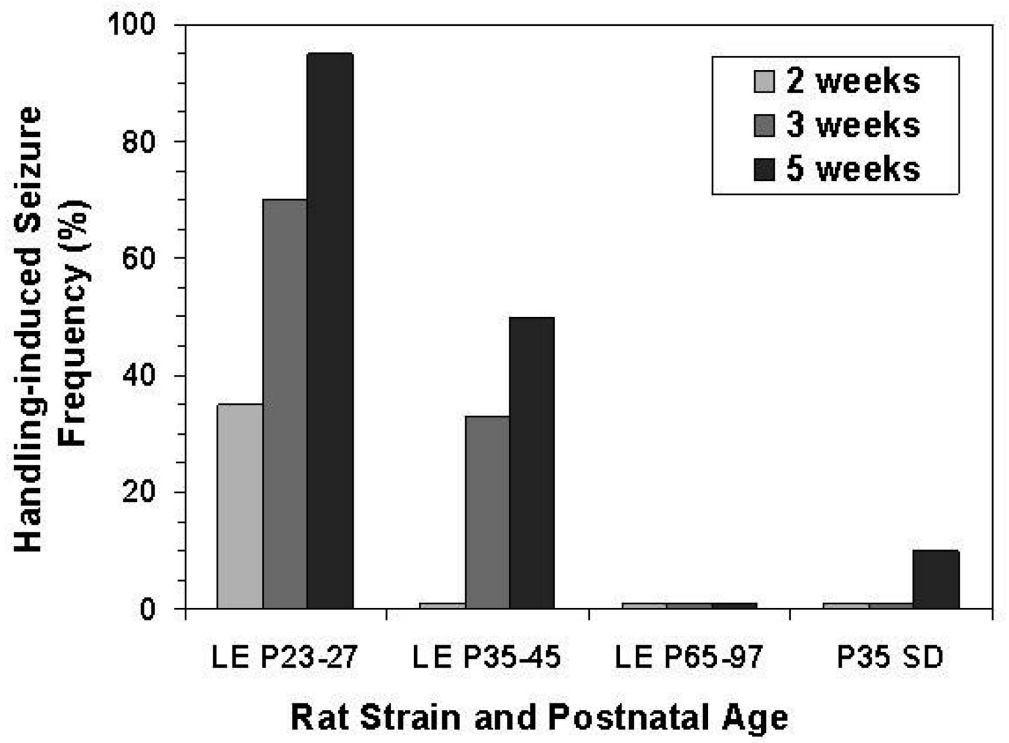

Figure 1.

Fequency of withdrawal seizures were determined to assess alcohol withdrawal severity in rats fed alcohol as part of an ethanol-containing liquid diet starting at different postnatal ages (P). After periods of 2, 3 or 5 weeks of alcohol consumption, ethanol consumption was terminated and animals were assessed for escalating stereotypic pattern of induced hyperreflexia, running episodes and convulsive seizures with relatively mild handling. Rats began alcohol consumption within specific age ranges: P23-27 ( N=30), P35-45 (N=30) and P65-97 ( $\mathrm{N}=15)$ and withdrawal severity was assessed after the specified number of weeks consuming the ethanol-containing diet. For comparison, frequency of withdrawal seizures was also determined for $\mathrm{P} 35 \mathrm{SD}$ rats $(\mathrm{N}=12)$. 


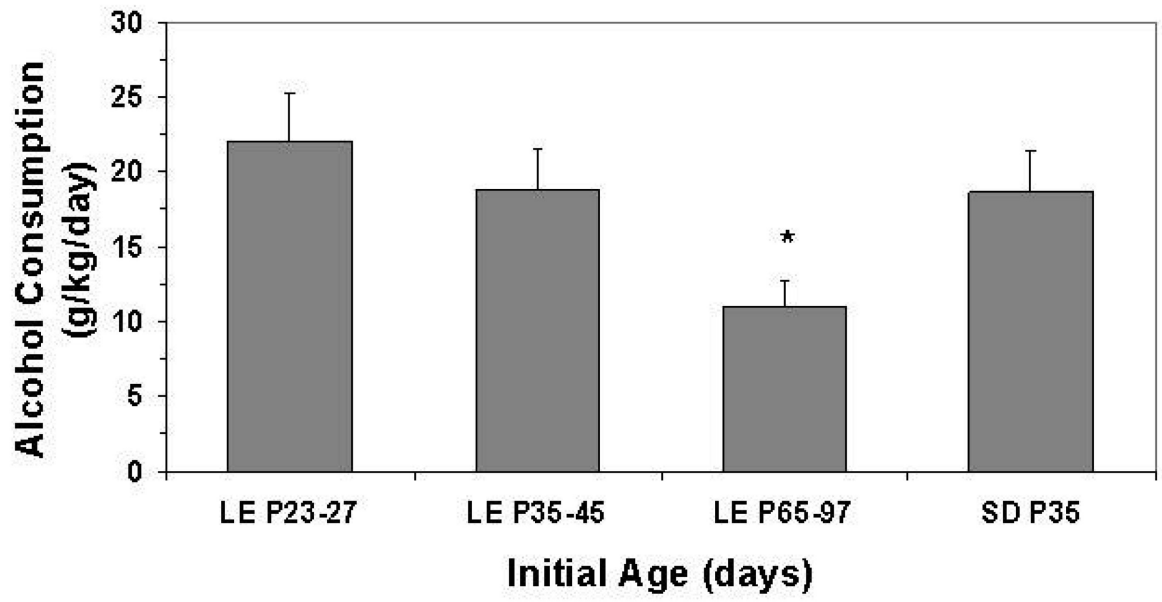

Figure 2.

Average alcohol consumption (g ethanol per day) was determined and normalized per body weight $(\mathrm{kg})$. Results are means \pm SEM and the age indicated represents the age at which the rat cohort began alcohol consumption. *Alcohol consumption for adult LE rats was significantly lower than that of LE juveniles $(\mathrm{p}<0.001)$ and LE adolescents $(\mathrm{p}<0.01)$. There was no significant difference in consumption between adolescent LE rats and adolescent SD rats. 


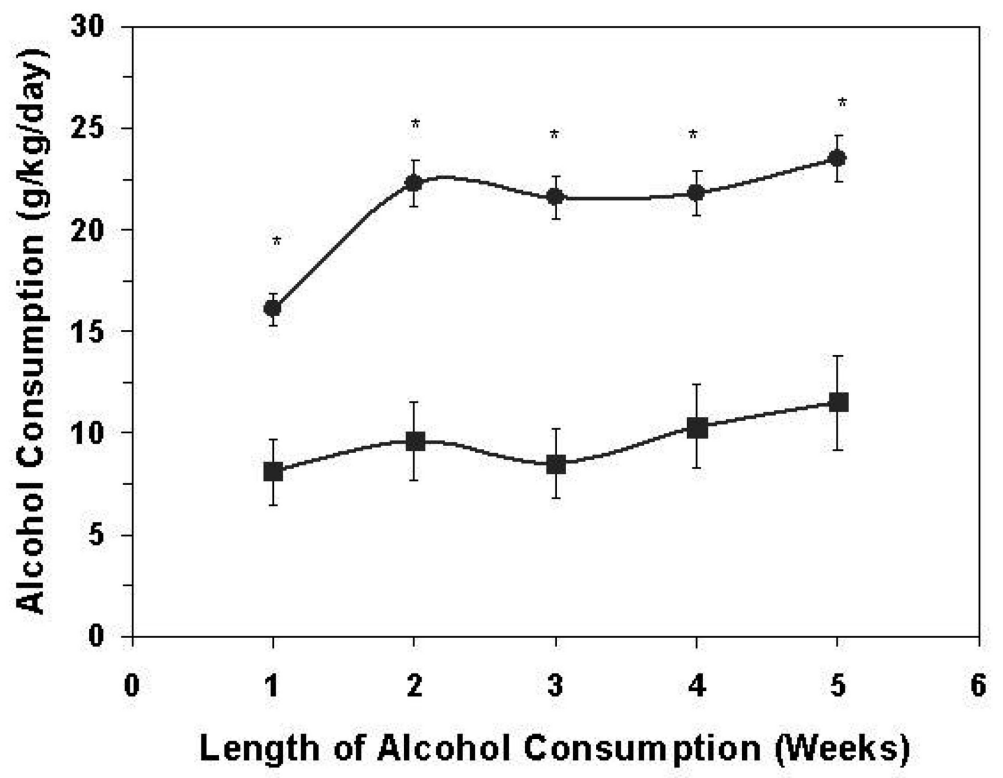

Figure 3.

Average alcohol consumption (g ethanol per day) was determined and normalized per body weight $(\mathrm{kg}$ ) for LE rats starting alcohol consumption at either P25 (circles) or P90 (squares). Results are means \pm SEM (N=8-10). Time zero represents the day alcohol consumption began and results are presented by week after alcohol consumption began. Rats that began consumption at P25 had significantly higher $(\mathrm{p}<0.001)$ levels of normalized consumption at each time point compared to the consumption of rats that began consumption at P90. 


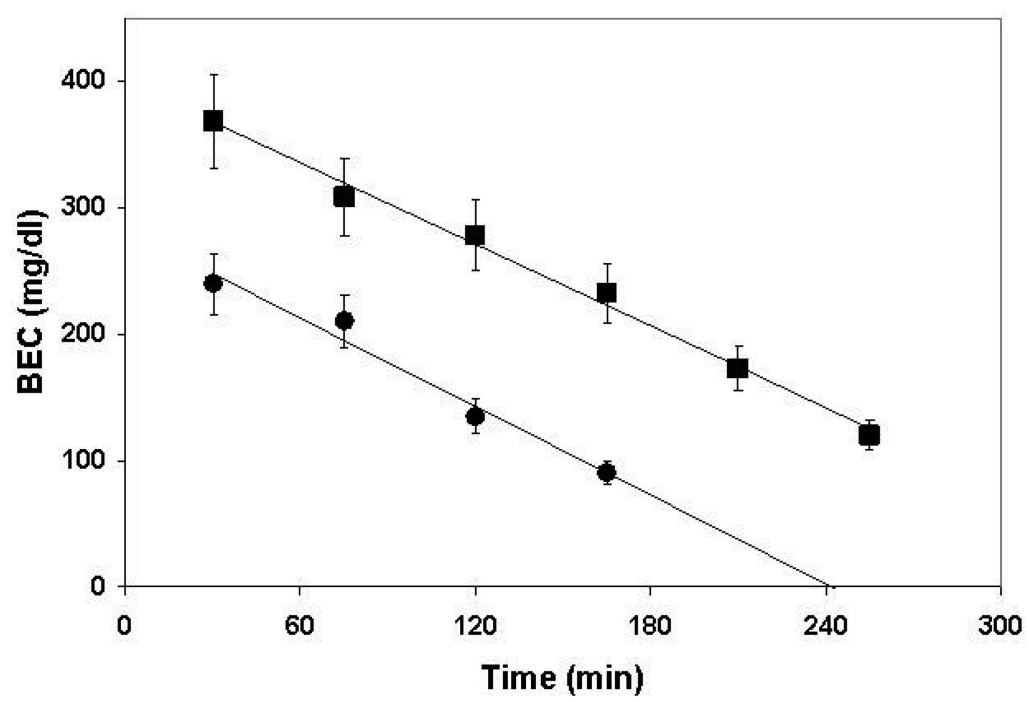

Figure 4.

Mean blood ethanol concentrations (BEC) of ethanol-naïve juvenile (circles) and young adult (squares) LE rats following a single injection with ethanol (2.5g/kg body weight, ip). Blood was collected from the tail vein at various times after injection and analyzed by gas chromatography to determine the ethanol concentration. Values represent the mean \pm SEM. Juvenile rats $(\mathrm{N}=18)$ had significantly lower $(\mathrm{p}<0.01)$ BEC than the adults $(\mathrm{N}=12)$ at each time point. 


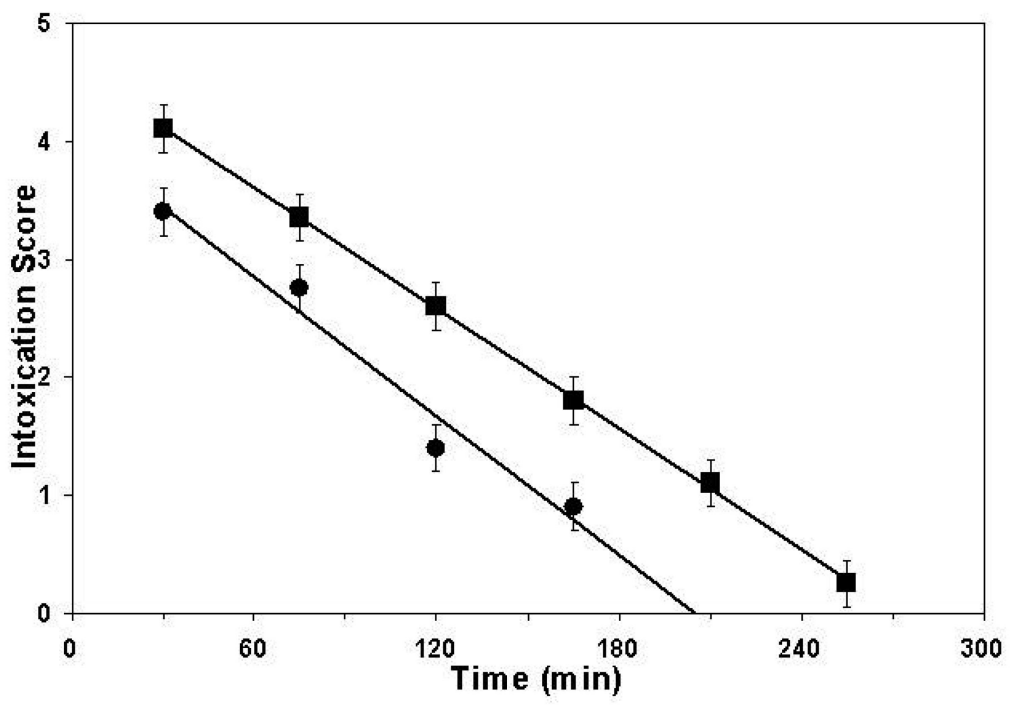

Figure 5.

Mean intoxication scores of ethanol-naïve juvenile (circles) and young adult (squares) LE rats after injection with ethanol $(2.5 \mathrm{~g} / \mathrm{kg}$ body weight, ip). Values represent means \pm SEM. Adults $(\mathrm{N}=12)$ had significantly higher $(\mathrm{p}<0.01)$ intoxication scores than juveniles $(\mathrm{N}=18)$ at each time point. 


\section{Table 1}

Effects of chronic alcohol consumption on body weight

\begin{tabular}{|c|c|c|c|c|}
\hline \multirow[b]{3}{*}{ Strain, Age } & \multicolumn{4}{|c|}{ Body Weight (g) } \\
\hline & \multicolumn{2}{|c|}{ Pair-fed } & \multicolumn{2}{|c|}{ Ethanol-fed } \\
\hline & $\underline{\text { Initial }}$ & Final & Initial & $\underline{\text { Final }}$ \\
\hline LE, P25 & $59 \pm 3$ & $164 \pm 9$ & $61 \pm 4$ & $138 \pm 5^{*}$ \\
\hline LE, P35 & $115 \pm 3$ & $240 \pm 5$ & $115 \pm 2$ & $191 \pm 15^{*}$ \\
\hline LE, P90 & $344 \pm 17$ & $509 \pm 25$ & $350 \pm 12$ & $422 \pm 14^{*}$ \\
\hline SD, P35 & $105 \pm 8$ & $230 \pm 18$ & $107 \pm 7$ & $197 \pm 12^{*}$ \\
\hline
\end{tabular}

Results are presented for one representative series of Long-Evans (LE) and one age of Sprague-Dawley (SD) rats weighed before (Initial) and then after being maintained on an ethanol-containing diet (Ethanol-fed) or a control diet (Pair-fed) for 5 weeks. The postnatal (P) age (days) indicated is the age at which the rats began consuming the ethanol-containing diet. Values are mean $\pm \mathrm{SD}(\mathrm{N}=6)$.

* Comparison of final weights between ethanol-fed and pair-fed rats showed that ethanol-fed rats in each age group weighed significantly less than the corresponding pair-fed control rats ( $\mathrm{p}<0.01$ for P25 LE and $\mathrm{p}<0.001$ for P35 LE, P90 LE and P35 SD). 


\section{Table 2}

Alcohol dehydrogenase activities in liver and brain

\begin{tabular}{lll}
\hline & \multicolumn{2}{c}{ ADH Activities (U/mg protein) at Postnatal Age } \\
Organ, Isozyme & P25 LE & P90 LE \\
Liver ADH-3 & $0.036 \pm 0.001^{*}$ & $0.025 \pm 0.002$ \\
Liver ADH-2 & $0.015 \pm 0.001^{*}$ & $0.011 \pm 0.001$ \\
Brain ADH-2 & $0.0026 \pm 0.0002$ & $0.0025 \pm 0.0001$ \\
\hline
\end{tabular}

Liver and brain alcohol dehydrogenase (ADH) were determined using different substrates to distinguish ADH isozymes, ADH-2 and ADH-3. Tissues were all from ethanol-naive Long-Evans rats at two postnatal ages, P25 (juvenile) and P90 (adult). Activity is expressed in Units ( $\mu$ moles $\mathrm{NADH}$ produced/min) and values presented are mean $\pm \mathrm{SD}(\mathrm{N}=6)$.

* Liver ADH-2 and ADH-3 were significantly greater $(p<0.001)$ in liver preparations from P25 compared to P90 rats. There was no significant difference in Brain ADH-2 levels. 